Running Head: GOAL ORIENTATION AND ABILITY

\author{
Goal Orientation and Ability: \\ Interactive Effects on Self-Efficacy, Performance, and Knowledge
}

Bradford S. Bell and Steve W. J. Kozlowski

Michigan State University

Bell, B. S., \& Kozlowski, S. W. J. (2002). Goal orientation and ability: Interactive effects on self-efficacy, performance, and knowledge. Journal of Applied Psychology, 87, 497-505.

Send Correspondence to:

Bradford S. Bell

386 Ives Hall

Cornell University

Ithaca, NY 14853

Phone: 607-254-8054

FAX: 607-255-1836

E-mail: bb92@cornell.edu 


\begin{abstract}
This study examined the direct relationship of goal orientation -- and the interaction of goal orientation and cognitive ability -- with self-efficacy, performance, and knowledge in a learning context. The current paper argues that whether a particular type of goal orientation is adaptive or not adaptive depends on individuals' cognitive ability. Results indicated that the direct associations of learning and performance orientations were consistent with previous research. Learning orientation was positively related to selfefficacy, performance, and knowledge, while performance orientation was negatively related to only one outcome, performance. The interactions between goal orientation and ability also supported several hypotheses. As expected, learning orientation was generally adaptive for high ability individuals, but had no effect for low ability individuals. In contrast, the effects of performance orientation were contingent on both individuals' level of cognitive ability and the outcome examined. The implications of these results for future research on goal orientation are discussed.
\end{abstract}




\section{Goal Orientation and Ability: \\ Interactive Effects on Self-Efficacy, Performance, and Knowledge}

Recent theory and research have begun to emphasize the importance of motivational characteristics as useful predictors of learning and performance. For example, a considerable amount of research over the past decade has demonstrated the relationship between goal orientation and the affective, cognitive, and behavioral reactions of individuals in achievement settings, such as the classroom and in athletics (e.g., Duda \& Nicholls, 1992; Dweck \& Leggett, 1988). More recent research has shown that goal orientation has important implications in training and employment contexts as well (e.g., Fisher \& Ford, 1998; Kozlowski, Gully, Brown, Salas, Smith, \& Nason, 2001; VandeWalle, Brown, Cron, \& Slocum, 1999; VandeWalle \& Cummings, 1997). This research has established that goal orientation has a consistent direct relationship with a number of outcomes, including self-efficacy, feedback seeking, learning, and performance. However, what is less well known is whether and how motivational traits like goal orientation interact with other individual difference variables, such as ability, to influence such outcomes.

Cognitive ability is widely considered to be the single best predictor of learning and performance, especially on difficult and complex tasks (Hunter, 1986; Hunter \& Hunter, 1984; Ree \& Earles, 1991). For example, Ackerman, Kanfer, and Goff (1998) found that cognitive ability accounted for nearly $50 \%$ of the variance in task performance on a complex radar control simulation. Interestingly, past research on goal orientation has not directly examined the impact of cognitive ability on goal orientation - outcome relationships. Instead, researchers have typically sought to either treat the effects of cognitive ability as experimental error via randomization (e.g., Duda \& Nicholls, 1992; Dweck \& Leggett, 1988) or to control it statistically to demonstrate that goal orientation evidences effects on outcomes over and above the effects of cognitive ability (e.g., Fisher \& Ford, 1998; Phillips \& Gully, 1997).

Although the independent effects of ability and goal orientation are reasonably well established, there has been virtually no attention to an examination of their potential interactive effects. Yet, there are several reasons to expect that cognitive and motivational characteristics interact. First, there is the well- 
accepted truism that performance is a function of motivation X ability (e.g., Campbell, McCloy, Oppler, \& Sager, 1993). This truism simply captures the logic that ability in the absence of motivation or motivation in the absence of ability is insufficient to yield performance. Second, recent research supports attention to the interactive effects of cognitive ability and motivational constructs on learning and performance. Kanfer and Ackerman (1989), for example, have shown that goal setting has differential effects depending on individuals' levels of cognitive ability. And, third, perceptions of ability are central to the conceptual foundation of the goal orientation constructs, suggesting an avenue for theory-driven interactional hypotheses.

In the current study, we posit unique interactions between goal orientation and cognitive ability with learning outcomes of self-efficacy, performance, and knowledge (Kraiger, Ford, \& Salas, 1993). The present research contributes to the goal orientation literature by showing that the relationships between learning and performance orientations with these outcomes may differ depending on one's level of cognitive ability. We begin the paper with a review of the research on goal orientation, focusing on the relationship between learning and performance goal orientations and several learning-related outcomes. We then discuss the potential role of cognitive ability as a moderator of these relationships.

\section{Learning and Performance Goal Orientations}

Goal orientation is a construct originating in the educational literature that suggests that individuals hold either a learning or performance orientation toward tasks (e.g., Dweck, 1986, 1989). A learning orientation is characterized by a desire to increase one's competence by developing new skills and mastering new situations. In contrast, performance orientation reflects a desire to demonstrate one's competence to others and to be positively evaluated by others (Farr, Hofmann, \& Ringenbach, 1993).

Research has shown that the two types of goal orientation differentially influence how individuals respond to task difficulty and failure (Dweck, Hong, \& Chiu, 1993; Dweck \& Leggett, 1988; Elliott \& Dweck, 1988). Individuals with a learning orientation tend to pursue what researchers have called an adaptive response pattern. This response pattern is characterized by persistence in the face of failure, the use of more complex learning strategies, and the pursuit of difficult and challenging material and tasks. 
Performance orientation, however, is associated with what researchers have called a maladaptive response pattern. This response pattern is characterized by a greater propensity to withdraw from tasks (especially in the face of failure), less interest in difficult tasks, and the tendency to seek less challenging material and tasks on which success is likely. Consistent with these labels, research has generally shown that learning orientation is associated with more positive outcomes and performance orientation is related to either equivocal or negative outcomes (e.g., Button, Mathieu, \& Zajac, 1996; Colquitt \& Simmering, 1998; Duda \& Nicholls, 1992; Elliott \& Dweck, 1988; Elliot \& Harackiewicz, 1994; Fisher \& Ford, 1998; Phillips \& Gully, 1997; Greene \& Miller, 1996; Harackiewicz \& Elliot, 1993; Vandewalle et al., 1999). Goal Orientation and Learning-Related Outcomes

To demonstrate consistency with prior research, the current study examined direct associations between learning and performance orientations and individuals' self-efficacy, performance, and knowledge. Research has shown that high levels of learning orientation tend to buffer individuals from the negative effects of failure, thereby helping to increase or maintain self-efficacy (Button et al., 1996; Ford, Smith, Weissbein, Gully, \& Salas, 1998; Kozlowski et al., 2001; Phillips \& Gully, 1997). Research has also examined the relationship of learning orientation with a variety of performance outcomes. Phillips and Gully (1997) found a positive relationship between learning orientation and classroom exam scores, Button et al. (1996) found a positive relationship between learning orientation and grade point average, and VandeWalle et al. (1999) found a positive relationship between learning orientation and sales performance. Consistent with this prior research, we propose the following hypothesis:

Hypothesis 1: Learning orientation is positively related to individuals' self-efficacy, performance, and knowledge.

Whereas previous research on learning orientation has produced rather consistent findings, research on performance orientation has resulted in mixed and contradictory findings. For example, Phillips and Gully (1997) and Ford et al. (1998) found that performance orientation had a negative effect on individuals' self-efficacy. However, Button et al. (1996) found that performance orientation was unrelated to individuals' self-esteem. Button et al. (1996) also found that performance orientation was 
unrelated to student's grade point average, and VandeWalle et al. (1999) found that performance orientation was unrelated to sales performance. In addition, Bell, Mullins, Toney, and Kozlowski (1999) and Kozlowski et al. (2001) found performance orientation to be generally unrelated to both knowledge and performance. Based on this past research, we predict the following:

Hypothesis 2: Performance orientation is not significantly related to individuals' self-efficacy, performance, and knowledge.

\section{Goal Orientation and Ability}

Research has found that goal orientation is linked to an individual's implicit theory of ability (Button et al., 1996; Dweck \& Leggett, 1988). Individuals with a performance orientation tend to hold an entity theory about their ability; they view ability as a fixed, uncontrollable personal attribute. In contrast, individuals with a learning orientation tend to hold an incremental theory about their ability; they view ability as a malleable attribute that can be developed through effort and experience.

Moreover, it has been argued that the adaptive and maladaptive response patterns associated with the two types of goal orientation emerge on the basis of these different beliefs about ability (Dweck et al., 1993). With a learning orientation, for example, effort is viewed as a means for activating current ability for task achievement and as a means for developing the ability needed for future task mastery. With a performance orientation, however, ability is perceived as a fixed attribute. Therefore, individuals with high levels of performance orientation are unlikely to view effort as a means for developing the ability needed for task mastery. In addition, performance-oriented individuals view effort as an indicator of low ability because they reason that a high-ability person would not need to try so hard to accomplish a task. The result is that individuals with high performance orientation are likely to put forth less effort on a task.

Due to the theoretical link between goal orientation and individuals' views of the nature of ability, a number of studies have examined the influence of perceived ability on the effects of goal orientation (e.g., Kaplan \& Midgley, 1997; Miller, Behrens, Greene, \& Newman, 1993). This research has typically examined the moderating effect of perceived ability on the relationship between goal orientation and behavior. This research has not only produced mixed findings but has also been limited 
by its methodology. Typically, individuals are categorized as learning oriented or performance oriented using a median split technique. This is conceptually problematic in that it places learning and performance orientations on a single continuum, whereas recent research has shown that it is more appropriate to treat learning and performance orientations as distinct and independent constructs (Button et al., 1996; VandeWalle, 1997). This technique is also methodologically problematic because it restricts variance and reduces the power to detect interactions (Aiken \& West, 1991). Thus, we actually know relatively little about the interaction between goal orientation and ability and their relationship with selfefficacy, performance, and knowledge (for an exception see Hofmann, 1993).

The present research, therefore, examines in more detail the interaction between goal orientation and individuals' level of cognitive ability. We argue that cognitive ability moderates the relationship between an individual's goal orientation and his or her self-efficacy, performance, and knowledge in learning or achievement situations. We posit that whether a particular type of goal orientation, and its associated response pattern, is adaptive or maladaptive depends on an individual's level of ability. Our theoretical position is (a) that learning orientation is generally adaptive for individuals with high cognitive ability, but is maladaptive for individuals with low cognitive ability; and (b) that performance orientation is generally adaptive for individuals with low cognitive ability, but is maladaptive for individuals with high cognitive ability. In the following section, we explicate the rationale for our hypotheses.

\section{Cognitive Ability as a Moderator of Goal Orientation-Outcome Relationships}

Self-efficacy. Previous goal orientation research has tended to focus on the amount of effort put forth by individuals with different levels of learning and performance orientations. We believe it is important to also consider how individuals with different levels of goal orientation direct that effort. Individuals with high learning orientation tend to pursue challenging and difficult task content and learning experiences. High ability individuals have the capabilities to do well on the difficult aspects of tasks and therefore are expected to experience high levels of self-efficacy. Low ability individuals, on the other hand, can be expected to do very poorly on complex tasks, thereby leading to lower levels of selfefficacy. Although they may put a great deal of effort into the task, they do not have the cognitive 
resources to direct that effort appropriately. Research has shown that high levels of learning orientation tend to buffer individuals from the negative effects of failure (Button et al., 1996). Therefore, when low ability individuals have high levels of learning orientation, their poor performance on more difficult aspects of the task may not have a strong negative impact on their self-efficacy, but it will not increase it. Consistent with these arguments, we hypothesize the following:

Hypothesis 3: Learning orientation is positively related to the self-efficacy of high ability individuals, but negatively related to or unrelated to the self-efficacy of low ability individuals.

Prior research on the relationship between performance orientation and self-efficacy has produced mixed findings. Even in those studies that have found a significant relationship between performance orientation and self-efficacy, the relationship has been rather weak (Ford et. al., 1998: $\underline{r}=-.20$; Phillips \& Gully, 1997: $\underline{r}=-.14)$. We believe that a clearer relationship between performance orientation and selfefficacy may emerge when ability is considered. Although we argue that performance orientation typically leads to more positive outcomes for low ability individuals and more negative outcomes for high ability individuals, we suggest that a different pattern may emerge with self-efficacy. Performance orientated individuals strive to demonstrate their competence to others and tend to view less than perfect performance as indicative of failure and lower, nonmalleable ability (Dweck, 1989). Since low ability individuals generally make more mistakes and exhibit lower levels of performance, performance orientation should be negatively related to low ability individuals' self-efficacy. In contrast, high ability individuals generally make fewer mistakes and perform better. Therefore, performance orientation should be positively related to the self-efficacy of high ability individuals. Thus, we predict the following:

Hypothesis 4: Performance orientation is negatively related to the self-efficacy of low ability individuals and positively related to the self-efficacy of high ability individuals.

Knowledge and performance. It is generally assumed that the positive effects of learning orientation on individuals' learning and performance are due to its adaptive response pattern (Dweck \& Leggett, 1988; Elliott \& Dweck, 1988). Although we believe this response pattern is adaptive for high ability individuals, we argue that it may be less adaptive for low ability individuals because they are not 
as capable of benefiting from challenging task content and complex learning strategies. Numerous studies have found that learning orientation is a positive predictor of the use of more complex learning strategies (e.g., Anderman, Griesinger, \& Westerfield, 1998; Anderman \& Young, 1994; Elliot, McGregor, \& Gable, 1999; Fisher \& Ford, 1998; Miller, Greene, Montalvo, Ravindran, \& Nichols, 1996; Pintrich \& Garcia, 1991). Gagné, Briggs, and Wagner (1992) define a learning strategy as "an internal process by which learners select and modify their ways of attending, learning, remembering, and thinking" (p. 66). Research has shown that individuals with high learning orientation tend to engage in deep processing, which involves elaboration, critical thinking, and the integration of new information with prior knowledge and experience. In general, individuals with high learning orientation tend to engage in more effortful cognitive processes when learning a new task or knowledge domain. High ability individuals benefit from the use of more complex learning strategies, which help them to maximize their knowledge and performance. Low ability individuals, however, have fewer cognitive resources to properly apply or benefit from these complex learning strategies (Kanfer, 1991; Kanfer \& Ackerman, 1989; Kanfer, Ackerman, Murtha, Dugdale, \& Nelson, 1994). Instead, efforts to use such strategies may actually impede their learning and performance. Low ability individuals may benefit more from simpler learning strategies. Therefore, we propose the following hypotheses:

Hypothesis 5: Learning orientation is positively related to high ability individuals ' performance but negatively related to low ability individuals' performance.

Hypothesis 6: Learning orientation is positively related to high ability individuals' knowledge but negatively related to low ability individuals' knowledge.

We suggest that the relationship between performance orientation and knowledge and performance may also depend on an individual's level of cognitive ability. High performance oriented individuals tend to seek out less challenging tasks and material. This behavior is not adaptive for high ability individuals, who have the potential to learn much more from challenging and difficult task content. By taking on less challenging material or tasks, high ability individuals constrain or limit their development. For low ability individuals, however, the pursuit of less challenging material may be 
adaptive because this material is better suited for their ability level. In addition, research has found that performance orientation tends to be positively associated with the use of less complex learning strategies (e.g., Elliot et al., 1999; Fisher \& Ford, 1998 Greene \& Miller, 1996; Harackiewicz, Barron, \& Elliot, 1998; Miller et al., 1996; Pintrich \& Garcia, 1991). Individuals with a performance orientation tend to engage in surface processing, which involves the rehearsal and rote memorization of information. Such strategies applied to less challenging material, however, is well suited for low ability individuals. They may comprehend much more from less difficult material. Less challenging material is also less likely to overwhelm low ability individuals and may help them to apply their limited cognitive resources and more effectively regulate their performance. Simpler learning strategies may be adaptive and beneficial for low ability individuals, but maladaptive for high ability individuals. Thus, we hypothesize the following:

Hypothesis 7: Performance orientation is positively related to low ability individuals' performance but negatively related to high ability individuals' performance.

Hypothesis 8: Performance orientation is positively related to low ability individuals' knowledge but negatively related to high ability individuals' knowledge.

Method

\section{$\underline{\text { Participants }}$}

A total of 125 undergraduate college students from a large Midwestern university participated in the current study. Individuals received course credit for participation in a three-hour session in which they learned to operate a computer-based radar simulation and were paid $\$ 5$ for completing the goal orientation measures. Fifty-eight percent of the participants were female, and most (88.8 percent) of the participants were between 18 and 21 years old.

$\underline{\text { Task }}$

The task used in this research was a version of TANDEM (Dwyer, Hall, Volpe, Cannon-Bowers, \& Salas, 1992). TANDEM is PC-based, low fidelity simulation of a naval radar task. The simulation presents participants with multiple targets on the computer screen. Participants were required to learn how to perform a number of both basic and strategic tasks. With respect to the basic tasks, participants 
needed to learn to "hook" targets on the radar screen and then collect information to classify the target's characteristics. Then the participant needed to use this information to make an overall decision (take action/clear). Participants received points for correct decisions and lost points for incorrect decisions. Participants also needed to learn strategic skills. These skills involved preventing targets from crossing two perimeters located on the radar screen. Individuals needed to learn how to identify the perimeters, determine which targets were higher priority than others, and make trade-offs between targets that were higher or lower priority. Targets that crossed perimeters cost points.

Procedure

Participants attended two experimental sessions. In the first session, they learned to perform the radar simulation described above. The sessions were conducted with groups of one to 12 participants. All participants were volunteers who received course credit for their participation in the three-hour experiment. Participants were first presented with a brief demonstration of the simulation that outlined its features and decision rules. They were then shown how to use an on-line instruction manual that contained complete information about the simulation. After this brief demonstration, participants had an opportunity to familiarize themselves with the task in a short one-minute trial. They were then told that they would progress through nine study, practice, and feedback cycles, followed by an opportunity to demonstrate how much they had learned on a more difficult and complex version of the task.

Participants were given nine 5-minute practice trials to prepare for the generalization trial. They had two-minutes before each trial to review the on-line manual and two-minutes following each trial to review their feedback. Veridical feedback on all important aspects of the task was provided immediately following each practice trial. After the third and ninth practice trials, participants completed measures of self-efficacy and completed basic and strategic knowledge tests. They also received a 5-minute break following the third and ninth trials. After the second 5-minute break, participants were presented with a 10-minute generalization task that was more difficult and complex than the scenarios they had practiced.

The following semester the participants were invited to participate in a brief follow-up session designed to collect the individual difference measures of learning and performance trait goal orientations. ${ }^{1}$ 
The experimental sessions were conducted with five to twenty participants. The experimenter provided participants with brief instructions and distributed the goal orientation measures. When the participants were finished, the experimenter collected the measures and paid each individual $\$ 5$ for his or her participation. The follow-up sessions each lasted approximately twenty minutes.

\section{$\underline{\text { Measures }}$}

Learning and performance orientations. Trait learning and performance orientations were assessed using two 8-item scales developed by Button et al. (1996). Learning orientation items included "The opportunity to learn new things is important to me" and "I prefer to work on tasks that force me to learn new things." Performance orientation items included "I feel smart when I do something without making any mistakes" and "The opinions others have about how well I can do certain things are important to me." $(1=\underline{\text { strongly disagree }}$ to $5=\underline{\text { strongly agree })}$. Button et al. (1996) found that a two-factor model of goal orientation fit better than a one-factor model in four different samples. In addition, Button et al. (1996) provide construct validity evidence for the measures. They found the two goal orientation measures to be uncorrelated and systematically and meaningfully related to a number of relevant demographic and substantive variables. In the current study, reliability (coefficient alpha) was .77 for learning orientation and .73 for performance orientation. These reliabilities are consistent with past research that has used these scales (e.g., Button et al., 1996; Ford et al., 1998, Phillips \& Gully, 1997).

Cognitive ability. All participants were administered the Wonderlic Personnel Test at the beginning of the first experimental session. The Wonderlic Personnel Test is a well-known and widely used index of general cognitive ability, suitable for a wide range of work tasks. The Wonderlic assesses individuals' mathematical, verbal, logical reasoning, and spatial ability to create a measure of general mental ability. The user's manual for the Wonderlic (1992) offers predictive validities as high as .63, with reliability estimates from .73 to .95 , depending on the type of reliability estimated.

Self-efficacy. Following the third practice trial and the ninth practice trial, self-efficacy was assessed using an 8-item task specific self-report measure appropriate for the simulation (Ford et al., 1998; Kozlowski et al., 2001). This measure assesses self-efficacy with a Likert-type scale rather than 
with ratings of confidence about particular aspects of the task (Hysong \& Quinones, 1997; Lee \& Bobko, 1994). A sample item is "I am confident that I can cope with this simulation if it becomes more

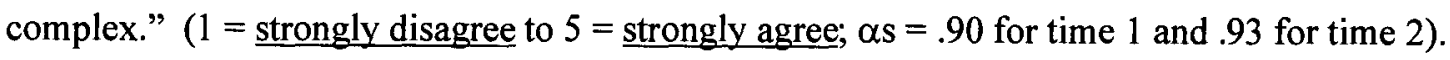
Individuals' self-efficacy scores at the two time periods were averaged to create a single measure. Knowledge. Following the third and ninth practice trials, participants completed basic and strategic knowledge tests. The basic knowledge test consisted of thirteen multiple-choice items focusing on the extent to which declarative knowledge (e.g., target characteristics; basic operating features of the task) about the task had been acquired. The strategic knowledge test consisted of fourteen multiple-choice items focusing on the extent to which participants had acquired strategic knowledge (e.g., locating the perimeters, identifying high priority targets) about the task. Individuals' basic and strategic knowledge test scores at both time periods were summed to create a single, composite measure of task knowledge.

Performance. Data were collected during the third and ninth practice trials that allowed assessments to be made of participants' performance on both the basic and strategic aspects of the task. Indicators of a participant's basic performance were the number of correct and incorrect decisions made. Strategic performance consisted of the number of times participants changed range and the number of markers hooked in an effort to identify the location of an invisible outer perimeter. Strategic performance also included the number of high priority targets processed. In addition, the same basic and strategic performance indicators were used to assess participants' performance on the final and more difficult generalization trial held at the end of the three-hour session. The generalization trial was longer in duration (10 minutes vs. 5 minutes), it included more targets on the screen (60 vs. 22), a greater number of targets popped up suddenly on the screen, and more targets threatened the outer perimeter. In addition, the rules were modified so that a greater number of points were deducted when targets crossed the visible inner perimeter (175 points) and the invisible outer perimeter (125). To achieve high levels of basic and strategic performance on this final trial, participants needed to adapt their strategies and generalize their skills. To create a single, composite measure of task performance, the basic and strategic performance 
indicators at the three time periods (trial three, trial nine, and generalization) were standardized and then summed using unit weights. ${ }^{2}$

\section{Data Analytic Strategy}

In the current study, the hypotheses were tested using hierarchical regression analyses. The first experimental session included a manipulation designed to help guide individuals through the learning process. This manipulation was not of interest in the current study, nor did it interact with learning orientation, performance orientation, or ability to produce any meaningful interactions. Therefore, to control for any effect it may have, it was entered as the first step in all hierarchical regression analyses reported in this paper. Cognitive ability, learning orientation, and performance orientation were entered next to test for their linear relations. The interaction terms between ability and learning orientation and performance orientation were entered in the third and final step. All variables were centered before creating the interaction terms (Cohen \& Cohen, 1983). Since each of the hypotheses was directional, onetailed tests of significance were used.

\section{Results}

Table 1 presents the means, standard deviations, and intercorrelations of variables included in the study. Results supported the treatment of learning and performance orientations as separate constructs. As expected, learning and performance orientation were not significantly correlated $(\underline{r}=.01)$ and were differentially related to most of the dependent variables. Table 2 presents the regression results predicting self-efficacy, performance, and knowledge. In the following sections, we present the results for the hypotheses, beginning with the direct relationships and then focusing on the interactions.

\section{Direct Relationships}

As expected, ability was significantly and positively related to almost all of the learning outcomes examined in the present study. Hypothesis 1 predicted that learning orientation is positively related to the outcomes examined in the present study. The regression analyses revealed that learning orientation was significantly and positively related to individuals' self-efficacy $(\underline{\beta}=.24, \underline{p}<.01)$, performance $(\underline{\beta}=.14, \underline{p}$ $<.01)$, and knowledge $(\underline{\beta}=.19, \underline{p}<.01)$. Thus, hypothesis 1 was supported. Hypothesis 2 predicted that 
performance orientation is not significantly related to any of the outcomes measured in the current study. As can be seen in Table 2, performance orientation had a significant negative relationship with only one outcome measure, task performance $(\underline{\beta}=-.12, \underline{p}<.05)$. Otherwise, performance orientation did not have a significant relationship with self-efficacy or knowledge. Hypothesis 2 was therefore generally supported. Overall, the direct relationships between learning and performance orientations and the outcomes examined in the present study are consistent with the findings of prior research.

\section{Goal Orientation x Ability Interactions}

Hypothesis 3 predicted that learning orientation is positively related to high ability individuals' self-efficacy but negatively related to or unrelated to low ability individuals' self-efficacy. The regression analyses revealed that learning orientation and ability significantly interacted in their relationship with self-efficacy $(\underline{\beta}=.18, \underline{p}<.05)$. As shown in Figure 1 , learning orientation was positively related to high ability individuals' self-efficacy. However, learning orientation did not relate to the self-efficacy of low ability participants. These results suggest that learning orientation was beneficial for high ability individuals but ineffective for low ability individuals, thereby supporting hypothesis 3 .

We argued in hypothesis 4 that performance orientation is negatively related to the self-efficacy of low ability individuals but positively related to the self-efficacy of high ability individuals. The regression results revealed that performance orientation and ability significantly interacted in their relationship with self-efficacy $(\beta=.17, \mathrm{p}<.05)$. As shown in Figure 2, performance orientation had a negative relationship with the self-efficacy of low ability individuals but a positive relationship with the self-efficacy of high ability individuals. Thus, hypothesis 4 was supported.

Hypotheses 5 and 6 focused on the interactive relationship of learning orientation and ability with performance and knowledge, respectively. We argued that learning orientation is positively related to high ability individuals' performance and knowledge, but negatively related to low ability individuals' performance and knowledge. Consistent with hypothesis 5 , learning orientation and ability significantly interacted in their relationship with participants' performance $(\underline{\beta}=.26, \underline{p}<.01)$. The nature of this 
interaction was such that learning orientation exhibited a positive relationship with the performance of high ability individuals but a very modest negative relationship with the performance of low ability individuals. This interaction is shown in Figure 3. Hypothesis 6, on the other hand, was unsupported. The regression analyses revealed that learning orientation and ability did not significantly interact in their relationship with participants' knowledge $(\underline{\beta}=.09, \underline{\mathrm{ns}})$.

Hypotheses 7 and 8 predicted that performance orientation is negatively related to high ability individuals' performance and knowledge, but positively related to low ability individuals' performance and knowledge. Consistent with hypothesis 7 , the results revealed that performance orientation and ability significantly interacted in their relationship with individuals' performance $(\underline{\beta}=-.13, \underline{p}<.10)$. The nature of this interaction was such that low ability individuals' performance was relatively unaffected by their level of performance orientation, but high ability individuals exhibited a clear performance decrement as their performance orientation increased. This interaction is displayed is Figure 4. Contrary to hypothesis 8 , performance orientation and ability did not significantly interact to affect knowledge.

\section{Discussion}

Recent research has found that goal orientation affects a number of variables relevant to both employment and training contexts (Fisher \& Ford, 1998; Ford et al., 1998; Kozlowski et al., 2001; VandeWalle et al., 1999; VandeWalle \& Cummings, 1997). Overall, the results obtained in the present study are consistent with findings of previous research on goal orientation. As expected, learning orientation was significantly and positively related to individuals' self-efficacy, knowledge, and performance; whereas performance orientation only related negatively to individuals' performance. Overall, the direct relationships obtained in the present study supported the adaptive nature of learning orientation and maladaptive nature of performance orientation, thereby replicating the results of previous research.

As hypothesized, however, the pattern of results was quite different when ability was taken into consideration. We argued that because individuals' with high levels of learning orientation typically 
pursue more challenging material and tasks and tend to use more complex learning strategies, higher levels of learning orientation would be adaptive for high ability individuals but maladaptive for low ability individuals. Consistent with our expectations, learning orientation was significantly related to the self-efficacy of high ability individuals and unrelated to the self-efficacy of low ability individuals. Also consistent with our expectations, we found that learning orientation was positively related to the performance of high ability individuals. However, learning orientation exhibited a very modest negative relationship with the performance of low ability individuals, suggesting that learning orientation is not so much maladaptive as it is non-adaptive for the performance of low ability individuals.

We also hypothesized that performance orientation would interact with ability in its relationship with individuals' learning outcomes. First, we proposed that performance orientation is positively related to high ability individuals' self-efficacy but negatively related to low ability individuals' self-efficacy. This hypothesis was supported. Second, we proposed that since performance oriented individuals typically pursue less challenging material and tasks and tend to use less complex learning strategies, performance orientation is positively related to low ability individuals' performance and knowledge but negatively related to high ability individuals' performance and knowledge. Providing partial support for our hypothesis, we found that performance orientation was negatively related to high ability individuals' performance. However, we also found that performance orientation was generally unrelated to the performance of low ability individuals. Thus, consistent with our expectations, the effects of performance orientation differed depending on an individual's level of cognitive ability and the outcome examined. Implications

The results of the present study suggest that the relationship of learning and performance orientations with individuals' learning-related outcomes may not be as straightforward as previously assumed. Past research on goal orientation has typically associated learning orientation with an adaptive response pattern and positive outcomes, and has associated performance orientation with a maladaptive response pattern and equivocal or negative outcomes. If one focused only on the direct relationships of the current study, one would arrive at same conclusion. However, when ability is considered, the pattern 
of results that emerges is different. Learning orientation was generally adaptive for high ability individuals but not adaptive for low ability individuals, and the effects of performance orientation were contingent on both individuals' level of cognitive ability and the outcome examined.

These findings suggest that it is potentially important for future theoretical and empirical work on goal orientation to explicitly consider the impact of cognitive ability. Clearly, an important question raised by the present findings is how robust are the patterns of interaction between goal orientation and cognitive ability? In particular, future research should attempt to identify the boundaries of the interactions observed in the present study. For example, we believe that task complexity may be a boundary condition on the results obtained in the present study. Previous research on goal orientation has often utilized relatively simple tasks, which may constrain the potential for ability to have an impact. Thus, it may be the case that goal orientation and ability exhibit direct relationships but no interaction on less complex tasks. However, in more complex learning environments we would anticipate that the interactions observed in this research would be more likely to hold. We regard an investigation of this issue as a logical next step for this research. In addition, future research should examine the impact of goal orientation-ability interactions on various process variables that may underlie the effects observed in the current study. Past research suggests that the effects of goal orientation may be explained by its impact on individuals' use of different learning strategies, goal choice, and self-efficacy (Brett \& VandeWalle, 1999; Fisher \& Ford, 1997; Phillips \& Gully, 1997). Because the current study was designed as a preliminary examination of the interactive effects of goal orientation and ability, we did not present or test a causal model. However, we believe that future examinations of mediating variables will prove valuable in advancing our understanding of the multiplicative effects of goal orientation and ability. Limitations

A few limitations of the current study should be noted. First, the current study employed a synthetic task, student participants, and was conducted in a laboratory setting. As a result, it is important for future research to examine goal orientation-ability interactions in a variety of settings to ascertain the generalizability of our findings. Another potential limitation concerns the fact that goal orientation was 
measured several months after the first experimental session. We do not perceive the time difference between the two sessions as a critical issue, however, because the differences in time and setting served to decouple the assessment of the goal orientation traits from any cues associated with the learning setting. Further, analyses showed that there were no significant differences between individuals who did and did not return for the second session.

It is also important to note a potential conceptual and practical dilemma that results from the orthogonality of learning and performance orientations. What if a person is high on both learning and performance orientations? Due to the fact that the two dimensions are unrelated, this combination of orientations is possible but relatively rare (Dweck \& Leggett, 1988; Tabernero \& Wood, 1999). However, in these situations, it may be useful to attempt to facilitate an individual to adopt the orientation that is most useful for his or her particular ability level. The results of current study suggest, for example, that to enhance performance high ability individuals should be encouraged to adopt a learning orientation and low ability individuals should be encouraged to adopt a performance orientation. Although in the current study the situation was held constant, past research has found that certain situational cues, such as goals, can facilitate the adoption of adaptive and maladaptive response patterns (e.g., Bell et al., 1999).

\section{Conclusion}

A considerable amount of research in recent years has demonstrated the importance of goal orientation in training and employment contexts. This research has typically found that learning orientation leads to positive outcomes and performance orientation leads to either equivocal or negative outcomes. Despite the widely held belief that the effects of motivation on learning and performance depend, at least in part, on individuals' cognitive ability, the impact of ability on goal orientation-outcome relationships has been relatively unexplored. Consistent with expectations, the current study found that whether a particular type of goal orientation was adaptive or not adaptive for different learning outcomes was related to an individual's level of cognitive ability. These findings suggest that future research is needed to explore the robustness of this interaction and potential boundary factors that may influence the nature of the impact of learning and performance orientations on learning outcomes. 


\section{References}

Aiken, L. S., \& West, S. G. (1991). Multiple regression: Testing and interpreting interactions. Newbury Park, CA: Sage Publications.

Ackerman, P. L., Kanfer, R., \& Goff, M. (1995). Cognitive and noncognitive determinants and consequences of complex skill acquisition. Journal of Experimental Psychology: Applied, 4, 270-304.

Anderman, E. M., Griesinger, T., \& Westerfield, G. (1998). Motivation and cheating during early adolescence. Journal of Educational Psychology, 90, 84-93.

Anderman, E. M., \& Young, A. J. (1994). Motivation and strategy use in science: Individual differences and classroom effects. Journal of Research in Science Teaching, 31, 811-831.

Bell, B. S., Mullins, M. E., Toney, R. J., \& Kozlowski, S. W. J. (1999). Goal orientation: Elaborating the effects of state and trait conceptualizations. Paper presented at the Fourteenth Annual Conference of the Society for Industrial and Organizational Psychology, Atlanta, GA.

Brett, J. F., \& VandeWalle, D. (1999). Goal orientation and goal content as predictors of performance in a training program. Journal of Applied Psychology, 84, 863-873.

Button, S. B., Mathieu, J. E., \& Zajac, D. M. (1996). Goal orientation in organizational research: A conceptual and empirical foundation. Organizational Behavior and Human Decision Processes, 67, 2648.

Campbell, J. P., McCloy, R. A., Oppler, S. H., \& Sager, C. E. (1993). A theory of performance. In N. Schmitt \& W. C. Borman and Associates, Personnel selection in organizations (pp. 35-70). San Francisco, CA: Jossey-Bass.

Cohen, J., \& Cohen, P. (1983). Applied multiple regression/correlation analysis for the behavioral sciences. Hillsdale, NJ: Lawrence Erlbaum.

Colquitt, J. A., \& Simmering, M. J. (1998). Conscientiousness, goal orientation, and motivation to learn during the learning process: A longitudinal study. Journal of Applied Psychology, 83, 654-665.

Duda, J. L., \& Nicholls, J. G. (1992). Dimensions of achievement motivation in schoolwork and sport. Journal of Educational Psychology, 84, 290-299. 
Dweck, C. S. (1986). Motivational processes affecting learning. American Psychologist, 41, 1040-1048.

Dweck, C. S. (1989). Motivation. In A. Lesgold \& R. Glaser (Eds.), Foundations for a psychology of education (pp. 87-136). Hillsdale, NJ: Erlbaum.

Dweck, C. S., Hong, Y., \& Chiu, C. (1993). Implicit theories: Individual differences in the likelihood and meaning of dispositional inference. Personality and Social Psychology Bulletin, 19, 644656.

Dweck, C. S., \& Leggett, E. L. (1988). A social-cognitive approach to motivation and personality. Psychological Review, 95, 256-273.

Dwyer, D. J., Hall, J. K., Volpe, C., Cannon-Bowers, J. A., \& Salas, E. (1992, September). $\underline{A}$ performance assessment task for examining tactical decision making under stress (Spec. Rep. No. 92002). Orlando, FL: Naval Training Systems Center, Human Factors Division.

Elliot, A. J., \& Harackiewicz, J. M. (1994). Goal setting, achievement orientation, and intrinsic motivation: A mediational analysis. Journal of Personality and Social Psychology, 54, 5-12.

Elliott, E. S., \& Dweck, C. S. (1988). Goals: An approach to motivation and achievement. Journal of Personality and Social Psychology, 54, 5-12.

Elliott, A. J., McGregor, H. A., \& Gable, S. (1999). Achievement goals, study strategies, and exam performance: A mediational analysis. Journal of Educational Psychology, 91, 549-563.

Farr, J. L., Hofmann, D. A., \& Ringenbach, K. L. (1993). Goal orientation and action control theory: Implications for industrial and organizational psychology. In C. L. Cooper \& I. T. Robertson (Eds.), International review of industrial and organizational psychology (pp. 193-232). New York, NY: Wiley.

Fisher, S. L., \& Ford, J. K. (1998). Differential effects of learning effort and goal orientation on two learning outcomes. Personnel Psychology, 51, 392-420. 
Ford, J. K., Smith, E. M., Weissbein, D. A., Gully, S. M., \& Salas, E. (1998). Relationships of goal orientation, metacognitive activity, and practice strategies with learning outcomes and transfer. Journal of Applied Psychology, 83, 218-233.

Gagné, R. M., Briggs, L. J., \& Wager, W. W. (1992). Principles of instructional design. Philadelphia: Harcourt Brace Jovanovich.

Greene, B. A., \& Miller, R. B. (1996). Influences on achievement: Goals, perceived ability, and cognitive engagement. Contemporary Educational Measurement, 21, 181-192.

Harackiewicz, J. M., Barron, K. E., \& Elliot, A. J. (1998). Rethinking achievement goals: When are they adaptive for college students and why? Educational Psychologist, 33, 1-21.

Harackiewicz, J. M., \& Elliot, A. J. (1993). Achievement goals and intrinsic motivation. Journal of Personality and Social Psychology, 65, 904-915.

Hofmann, D. A. (1993). The influence of goal orientation on task performance: A substantively meaningful suppressor variable. Journal of Applied Social Psychology, 23, 1827-1846.

Hunter, J. E. (1986). Cognitive ability, cognitive aptitudes, job knowledge, and job performance. Journal of Vocational Behavior, 29, 340-362.

Hunter, J. E., \& Hunter, R. F. (1984). Validity and utility of alternative predictors of job performance. Psychological Bulletin, 96, 73-98.

Hysong, S. J., \& Quinones, M. A. (1997). The relationship between self-efficacy and performance: A meta-analysis. Paper presented at the Twelfth Annual Conference of the Society for Industrial and Organizational Psychology, St. Louis, MO.

Kanfer, R. (1991). Motivation theory and organizational psychology. In M. D. Dunnette \& L. Hough (Eds.), Handbook of industrial and organizational psychology $\left(2^{\text {nd }}\right.$. Ed., Vol. 1, pp. 75-170). Palo Alto, CA: Consulting Psychologists Press.

Kanfer, R., \& Ackerman, P. L. (1989). Motivation and cognitive abilities: An integrative /aptitude-treatment interaction approach to skill acquisition." Journal of Applied PsychologyMonograph, 74, 657-690. 
Kanfer, R., Ackerman, P. L., Murtha, T. C., Dugdale, B., \& Nelson, L. (1994). Goal setting, conditions of practice, and task performance: A resource allocation perspective. Journal of Applied Psychology, 79, 826-835.

Kaplan, A., \& Midgley, C. (1997). The effect of achievement goals: Does level of perceived academic competence make a difference? Contemporary Educational Psychology, 22, 415-435.

Kozlowski, S. W. J., Gully, S. M., Brown, K. G., Salas, E., Smith, E. A., \& Nason, E. R. (2001). Effects of training goals and goal orientation traits on multi-dimensional training outcomes and performance adaptability. Organizational Behavior and Human Decision Processes, 85, 1-31.

Kraiger, K., Ford, J. K., \& Salas, E. (1993). Application of cognitive, skill-based, and affective theories of learning outcomes to new methods of training evaluation. Journal of Applied Psychology, 78. 311-328.

Lee, C., \& Bobko, P. (1994). Self-efficacy beliefs: Comparison of five measures. $\underline{\text { Journal of }}$ Applied Psychology, 79, 364-369.

Miller, R. B., Behrens, J. T., Greene, B. A., \& Newman, D. (1993). Goals and perceived ability: Impact on student valuing, self-regulation, and persistence. Contemporary Educational Psychology, 18, $2-14$.

Miller, R. B., Greene, B. A., Montalvo, G. P., Ravindran, B., \& Nichols, J. D. (1996). Engagement in academic work: The role of learning goals, future consequences, pleasing others, and perceived ability. Contemporary Educational Psychology, 21, 338-422.

Phillips, J. M., \& Gully, S. M. (1997). Role of goal orientation, ability, need for achievement, and locus of control in the self-efficacy and goal-setting process. Journal of Applied Psychology, 82, 792-802.

Pintrich, P. R., \& Garcia, T. (1994). Self-regulated learning in college students: Knowledge, strategies, and motivation. In P. Pintrich, D. Brown, \& C. Weinstein (Eds.), Student motivation, cognition, and learning (pp. 113-133). Hillsdale, NJ: Erlbaum. 
Ree, M. J., \& Earles, J. A. (1991). Predicting training success: Not much more than g. Personnel Psychology, 44, 321-332.

Tabernero, C., \& Wood, R. E. (1999). Implicit theories versus the social construal of ability in self-regulation and performance on a complex task. Organizational Behavior and Human Decision Processes, 78, 104-127.

VandeWalle, D. (1997). Development and validation of a work domain goal orientation instrument. Educational and Psychological Measurement, 57, 995-1015.

VandeWalle, D., Brown, S. P., Cron, W. L., \& Slocum, J. W. (1999). The influence of goal orientation and self-regulation tactics on sales performance: A longitudinal field test. Journal of Applied Psychology, 84, 249-259.

VandeWalle, D., \& Cummings, L. L. (1997). A test of the influence of goal orientation on the feedback-seeking process. Journal of Applied Psychology, 82, 390-400. 


\section{Author Note Page}

Bradford S. Bell, Department of Psychology, Michigan State University; Steve W. J. Kozlowski, Department of Psychology, Michigan State University.

We thank Daniel R. Ilgen for his helpful comments on earlier versions of this manuscript. We would also like to acknowledge the Naval Air Warfare Center Training Systems Division for support (N61339-96-K-0005, S. W. J. Kozlowski, Principle Investigator) of this research. The views expressed are those of the authors and do not necessarily represent the official position or policy of any organization.

Correspondence concerning this article should be addressed to Bradford S. Bell, 129 PYR, Michigan State University, East Lansing, MI 48824-1117. Electronic mail may be sent via Internet to bellbra1@msu.edu. 


\section{Footnotes}

${ }^{1}$ A total of 277 individuals participated in the first experimental session which was part of a larger study. The following semester, students from this original sample were invited to participate in the follow-up session designed to gather the goal orientation data. A total of 125 (45\%) students from the original sample returned for the second experimental session. Because we were measuring trait goal orientation, the time difference between the two sessions should not be an issue. In fact, the time difference acts to strengthen the validity of any significant results obtained. Analyses were performed to test for differences between individuals who did and did not return for the second session. It was found that those participants who did participate in both sessions were not significantly different from those who did not in terms of demographics, including age, gender, and self-report GPA. In addition, there was not a significant difference between the two groups on a motivation scale administered at the end of the first experimental session (e.g., "I put forth effort to answer the questions accurately and honestly").

${ }^{2}$ Although we used a composite measure of task performance, it is important to note that participants' average performance improved across time, as would be expected. For example, participants' average scores were -154.40 in the third trial and 436.80 in the ninth trial. Using a median split technique, we also found that participant's performance improved across time regardless of whether they were low learning orientation $(\mathrm{T} 3=-209.59, \mathrm{~T} 9=413.38)$, high learning orientation $(\mathrm{T} 3=-74.31$, $\mathrm{T} 9=470.78)$, low performance orientation $(\mathrm{T} 3=-113.17, \mathrm{~T} 9=451.27)$, or high performance orientation $(\mathrm{T} 3=-196.29, \mathrm{~T} 9=422.10)$, although, as expected, there were mean differences depending on goal orientation. 
Table 1

Means, Standard Deviations, and Intercorrelations

\begin{tabular}{|c|c|c|c|c|c|c|c|c|}
\hline Variable & $\mathbf{M}$ & $\mathrm{SD}$ & 1 & 2 & 3 & 4 & 5 & 6 \\
\hline 1. Learning Orientation & 4.15 & 0.44 & -- & & & & & \\
\hline 2. Performance Orientation & 4.07 & 0.48 & .01 & -- & & & & \\
\hline 3. Ability & 25.86 & 4.49 & .12 & -.06 & -- & & & \\
\hline 4. Self-efficacy & 3.65 & 0.62 & $.27 * *$ & -.03 & $.28 * *$ & -- & & \\
\hline 5. Performance & 0.00 & 1.00 & .16 & -.16 & $.43 * *$ & $.53 * *$ & -- & \\
\hline 6. Knowledge & 35.84 & 6.61 & $.22 *$ & -.05 & $.46^{* *}$ & $.46^{* *}$ & $.61^{*}$ & -- \\
\hline
\end{tabular}

Note: ${ }^{*}$ Correlation is significant at the 0.05 level (2-tailed). ${ }^{* *}$ Correlation is significant at 0.01 level (2-tailed). 
Table 2

Hierarchical Regression Results: Predicting Self-efficacy, Performance, and Knowledge

\begin{tabular}{|c|c|c|c|c|}
\hline \multirow[b]{2}{*}{ Predictor/Step } & \multicolumn{2}{|c|}{$\beta$} & \multirow[b]{2}{*}{$\mathrm{R}^{2}$} & \multirow[b]{2}{*}{$\Delta \mathrm{R}^{2}$} \\
\hline & At Step & Final & & \\
\hline \multicolumn{5}{|l|}{ DV: Self-efficacy } \\
\hline 1. Ability & $.25^{* *}$ & $.21 * *$ & & \\
\hline Learning Orientation & $.24^{* *}$ & $.22 * *$ & & \\
\hline Performance Orientation & -.02 & -.08 & $.13^{* *}$ & $.13 * *$ \\
\hline 2. Ability $\mathrm{x}$ Learning Orientation & $.18^{*}$ & $.18^{*}$ & & \\
\hline Ability $x$ Performance Orientation & $.17^{*}$ & $.17^{*}$ & $.19 * *$ & $.06^{*}$ \\
\hline \multicolumn{5}{|l|}{ DV: Performance } \\
\hline 1. Ability & $.41 * *$ & $.33 * *$ & & \\
\hline Learning Orientation & $.14^{*}$ & $.19 * *$ & & \\
\hline Performance Orientation & $-.12^{\dagger}$ & $-.14^{*}$ & $.27 * *$ & $.22 * *$ \\
\hline \multirow{2}{*}{$\begin{array}{l}\text { 2. Ability } x \text { Learning Orientation } \\
\text { Ability } x \text { Performance Orientation }\end{array}$} & $.26^{* *}$ & $.26 * *$ & & \\
\hline & $-.13^{\dagger}$ & $-.13^{\dagger}$ & $.35 * *$ & $.08 * *$ \\
\hline \multicolumn{5}{|l|}{ DV: Knowledge } \\
\hline 1. Ability & $.44 * *$ & $.41 * *$ & & \\
\hline Learning Orientation & $.19 * *$ & $.20 * *$ & & \\
\hline Performance Orientation & -.02 & -.02 & $.28 * *$ & $.25 * *$ \\
\hline 2. Ability $\mathrm{x}$ Learning Orientation & .09 & .09 & & \\
\hline Ability $\mathrm{x}$ Performance Orientation & -.04 & -.04 & $.29 * *$ & .01 \\
\hline
\end{tabular}

Note: DV = dependent variable. Manipulation from experimental study controlled in all analyses reported above. $\beta$ is the standardized regression coefficient and significance levels are based on directional, one-tailed t-tests. Increments for variables entered at the $\Delta \mathrm{R}^{2}$ significance levels are based on F tests for that step. ${ }^{\dagger} \mathrm{p}<.10 .^{*} \mathrm{p}<.05 .{ }^{* *} \mathrm{p}<.01$. 


\section{Figure Captions}

Figure 1. Significant interaction between learning goal orientation and ability on individuals' selfefficacy.

Figure 2. Significant interaction between performance goal orientation and ability on individuals' selfefficacy.

Figure 3. Significant interaction between learning goal orientation and ability on individuals' performance.

Figure 4. Significant interaction between performance goal orientation and ability on individuals' performance. 


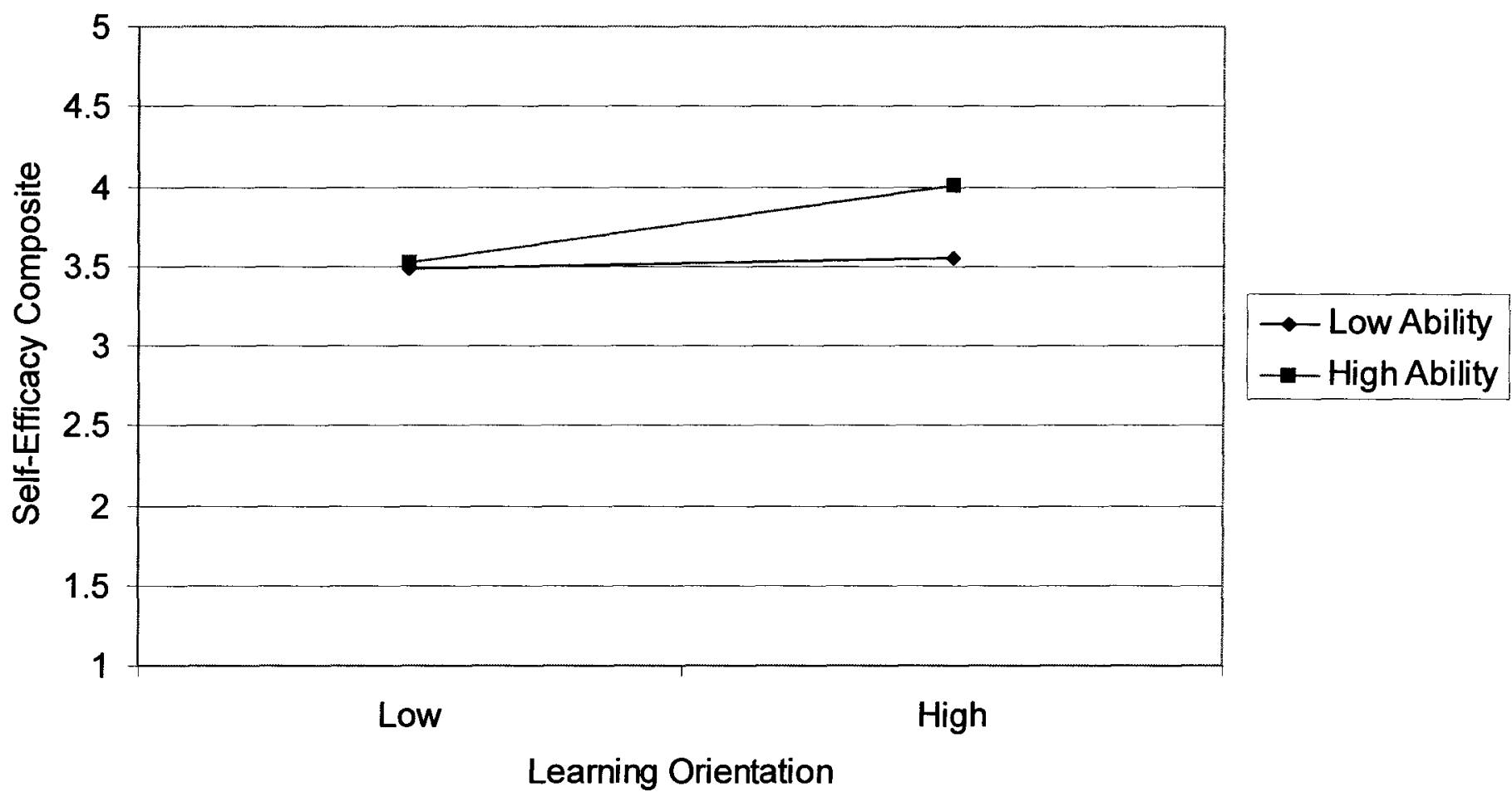




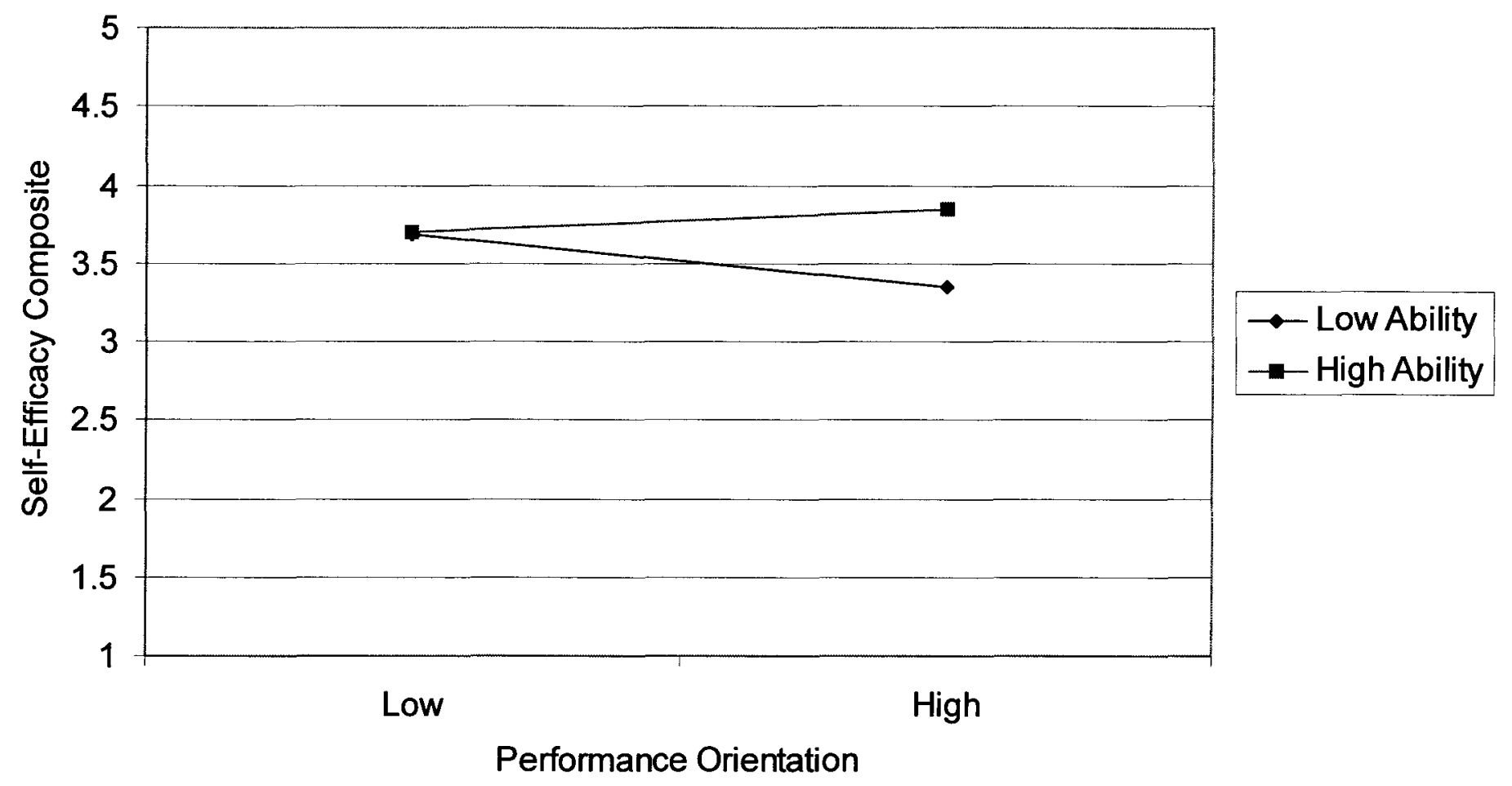




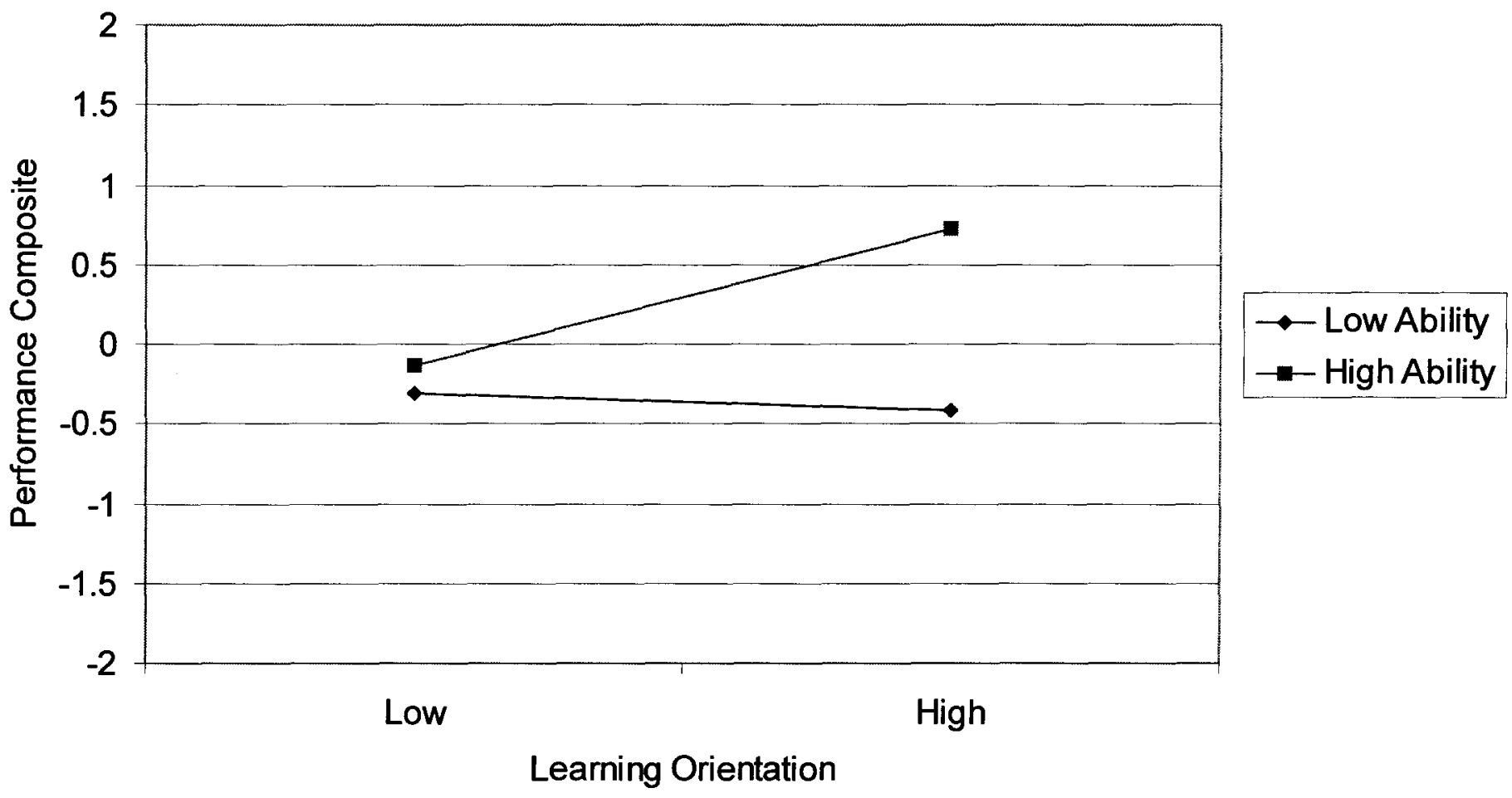




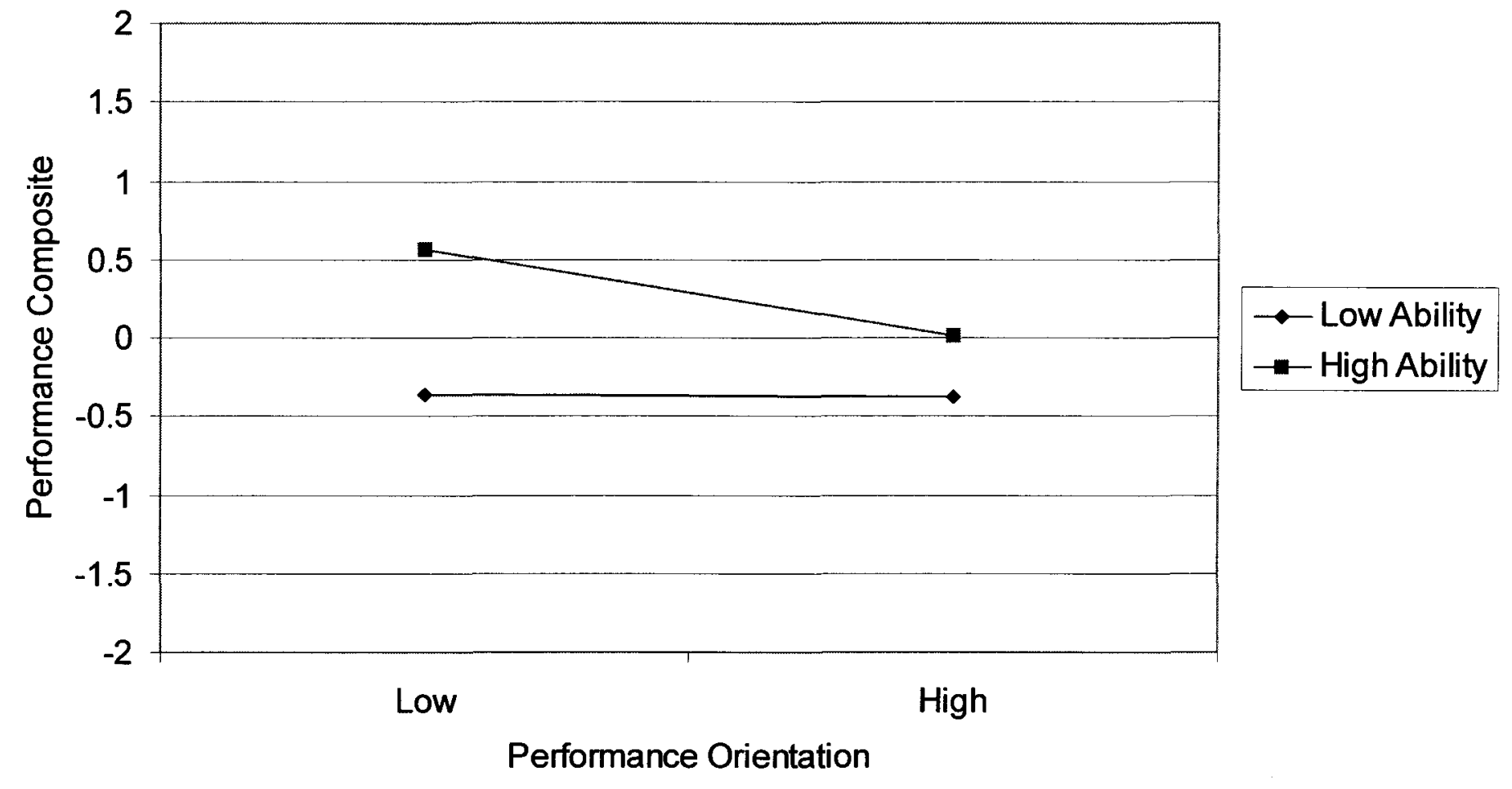

